\title{
Determination of $\alpha$ in the Cadmium Lined Irradiation Channel of the NIRR-1 for Use in $k_{o}$-ENAA
}

\author{
F. T. Sheyin ${ }^{*}$, M. O. A. Oladipo' ${ }^{1}$, S. A. Jonah ${ }^{1}$, U. Sadiq ${ }^{2}$ \\ ${ }^{1}$ Centre for Energy Research and Training, Ahmadu Bello University, Zaria, Nigeria \\ ${ }^{2}$ Department of Physics, Ahmadu Bello University, Zaria, Nigeria \\ Email: ${ }^{*}$ sheyin@abu.edu.ng
}

Received 28 May 2015; accepted 28 July 2015; published 31 July 2015

Copyright (C) 2015 by authors and Scientific Research Publishing Inc.

This work is licensed under the Creative Commons Attribution International License (CC BY). http://creativecommons.org/licenses/by/4.0/

(c) (i) Open Access

\begin{abstract}
The epithermal neutron shape factor $(\alpha)$ was determined in the permanent cadmium lined irradiation channel installed in the large outer irradiation site of the Nigeria Research Reactor-1 (NIRR1) by the cadmium covered multimonitor method using the monitors $\mathrm{Al}-0.1 \% \mathrm{Au}, \mathrm{Zr}$ and $\mathrm{Zn}$ thin foils and Mo thin wire and was found to be $-0.137 \pm 0.018$. The high negative value of $\alpha$ indicates a hardened epithermal neutron spectrum in the cadmium lined irradiation channel. The $\alpha$ value obtained was used in the single comparator method of ENAA ( $k_{o}$-ENAA) for the determination of the concentrations of elements in the standard reference material NIST 1515 Apple leaves using Al-0.1\% Au thin foil as the single comparator. The concentrations of the elements $\mathrm{Sm}$ and $\mathrm{Br}$ were determined in the NIST 1515 Apple leaves because of their high $Q_{o}$ values and are in good agreement with the certified values.
\end{abstract}

\section{Keywords}

$\alpha$ Value, Cadmium Covered Multimonitor Method, Cadmium Lined Irradiation Channel, $\boldsymbol{k}_{\boldsymbol{o}}$-ENAA

\section{Introduction}

The $30 \mathrm{~kW}$ Nigeria Research Reactor-1 (NIRR-1) is located at the Centre for Energy Research and Training, Ahmadu Bello University, Zaria, Nigeria. It is an undermoderated tank-in-pool commercial Miniature Neutron Source Reactor (MNSR) that is used for neutron activation analysis (NAA). The reactor core has highly enriched uranium (90.2\%) as fuel, light water as coolant and moderator and metallic beryllium as reflector. The NIRR-1 has 10 irradiation sites (5 small inner, 3 small outer and 2 large outer). However, only six irradiation

\footnotetext{
${ }^{*}$ Corresponding author.
}

How to cite this paper: Sheyin, F.T., Oladipo, M.O.A., Jonah, S.A. and Sadiq, U. (2015) Determination of $\alpha$ in the Cadmium Lined Irradiation Channel of the NIRR-1 for Use in $k_{o}$-ENAA. World Journal of Nuclear Science and Technology, 5, $233-240$. 
sites are connected to the pneumatic transfer systems types A and B control desks: 4 small inner (B1, B2, B3 and A1), 1 small outer (B4) and 1 large outer (A3). The rabbit system type A is used for pneumatic transfer of samples into and out of the small inner irradiation sites A1 and the large outer irradiation site A3 with a permanent cadmium (Cd) lining of thickness $1.00 \mathrm{~mm}$, length $250.00 \mathrm{~mm}$ and cut-off energy of $0.55 \mathrm{eV}$. The rabbit system type B is used for the pneumatic transfer of samples into and out of the irradiation sites B1, B2, B3 and B4. At full operating power, the maximum thermal neutron fluxes in the inner and outer irradiation sites (excluding the Cd lined irradiation channel A3) are approximately $1 \times 10^{12} \mathrm{n} \cdot \mathrm{cm}^{-2} \cdot \mathrm{s}^{-1}$ and $5 \times 10^{11} \mathrm{n} \cdot \mathrm{cm}^{-2} \cdot \mathrm{s}^{-1}$ respectively. The schematic diagram of the top view of the reactor complex of the NIRR-1 is shown in Figure 1 [1].

The cadmium (Cd)-lined irradiation channel A3 was recently installed to include the capabilities of the NIRR-1 facilities for epithermal neutron activation analysis (ENAA) protocols. Consequently, there is a need to characterize the Cd-lined irradiation channel. In this work, the epithermal neutron shape factor $(\alpha)$ was determined in the Cd-lined irradiation channel for implementation of the single comparator method of epithermal neutron activation analysis $\left(k_{o}\right.$-ENAA). The cadmium covered multimonitor method was used for the determination of $\alpha$ in the irradiation channel.

In the cadmium covered multimonitor method, a set of $\mathrm{N}$ suitable $\alpha$ monitors are coirradiated under cadmium cover and the induced activities measured on an efficiency calibrated high purity germanium (HPGe) detector system. For elements having a cross section $\sigma(v) \propto 1 / v$ in the range up to $\approx 1.5 \mathrm{eV}, \alpha$ can be found as the slope $(-\alpha)$ of the straight line when plotting:

$$
\log \frac{\bar{E}_{r, i}^{-\alpha} \cdot\left(A_{s p, i}\right)_{\mathrm{Cd}}}{k_{o, \mathrm{Au}(i)} F_{\mathrm{Cd}, i} Q_{o}(\alpha)_{i} \varepsilon_{d, i}} \text { versus } \log \bar{E}_{r, i}
$$

where

$k_{o, \mathrm{Au}(i)}=k_{o}$-factors for the $i$ th monitor with respect to $\mathrm{Au}$,

$Q_{o}(\alpha)_{i}=$ resonance integral to thermal neutron cross section ratio in the actual irradiation site,

$\left(A_{s p, i}\right)_{\mathrm{Cd}}=\left[\frac{N_{p} / t_{c}}{S D C w}\right]_{\mathrm{Cd}}$ is the specific activity of the ith monitor the Cd index denotes Cd cover irradiation,

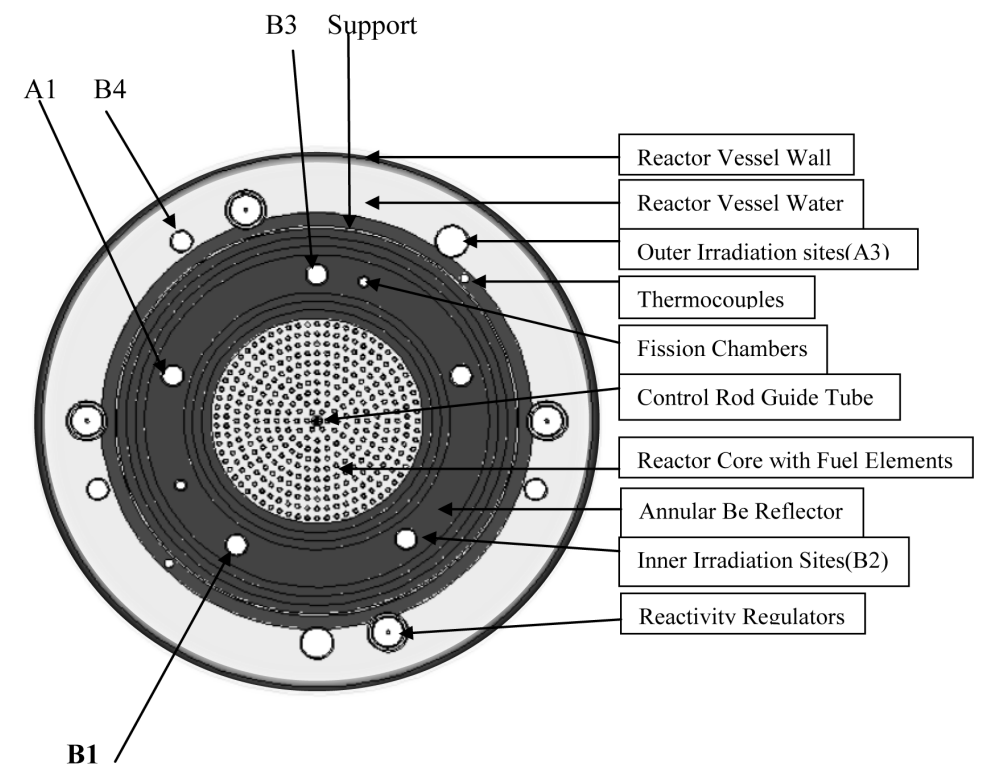

Figure 1. The schematic diagram of the top view of the reactor complex of the NIRR-1. A3 - cadmium lined irradiation channel, A1—small inner irradiation channel, B1-small inner irradiation channel, B2-small inner irradiation channel, B3-small inner irradiation channel, B4-small outer irradiation channel. 
$N_{p}=$ Net photopeak area (counts) of each monitor irradiated in Cd lined channel,

$S=\left(1-\mathrm{e}^{-\lambda t_{i}}\right)=$ saturation factor for each monitor,

$D=\mathrm{e}^{-\lambda t_{d}}=$ decay factor for each monitor,

$C=\left(\frac{1-\mathrm{e}^{-\lambda t_{c}}}{\lambda t_{c}}\right)=$ correction factor for decay during counting for each monitor,

$\lambda=$ decay constant, $t_{i}=$ irradiation time, $t_{d}=$ decay time, $t_{c}=$ counting time,

$w=$ mass of element in sample of thin foil or wire monitors irradiated (g),

$F_{C d, i}=$ cadmium epithermal neutron transmission factors for the ith nuclide,

$\varepsilon_{d, i}=$ full energy peak detector efficiency of the $i$ th nuclide,

$\varepsilon_{\gamma}=\gamma$-ray intensity,

$i=1,2, \cdots, N=$ number of nuclides,

$\bar{E}_{r, i}=$ average resonance energy of the $i$ th monitor.

The left hand term of Equation (1) is itself a function of $\alpha$, and thus an iterative procedure can be applied with square regression analysis to fit the experimental data to the straight lines for every iterative step [2].

Mathematically, the final $\alpha$ result of this iteration procedure is identical with solving for the value of $\alpha$ from the equation

$$
\alpha+\frac{\sum_{i=1}^{N}\left\{\left[\log \bar{E}_{r, i}-\frac{\sum_{i=1}^{N} \log \bar{E}_{r, i}}{N}\right]\left[\log T_{i}-\frac{\sum_{i=1}^{N} \log T_{i}}{N}\right]\right\}}{\sum_{i=1}^{N}\left[\log \bar{E}_{r, i}-\frac{\sum_{i=1}^{N} \log \bar{E}_{r, i}}{N}\right]^{2}}=0
$$

where $T_{i}=\frac{\bar{E}_{r, i}^{-\alpha} \cdot\left(A_{s p, i}\right)_{\mathrm{Cd}}}{k_{o, \mathrm{Au}(i)} F_{\mathrm{Cd}, i} Q_{o}(\alpha)_{i} \varepsilon_{d, i}}$,

$k_{o, \mathrm{Au}(i)}=k_{o}$ factors for the ith monitor with respect to $\mathrm{Au}$,

$\bar{E}_{r, i}=$ average resonance energy of the ith monitor,

$i=1,2, \cdots, N=$ number of nuclides.

\section{Materials and Methods}

The cadmium covered multimonitor method was use for the determination of $\alpha$ in the cadmium lined irradiation channel of the NIRR-1. One set of four monitors comprising of high purity Al-0.1\%Au, $\mathrm{Zr}$ and $\mathrm{Zn}$ thin foils and Mo thin wire were weighed, arranged in a small polyethylene thin film bag and then put inside a $25 \mathrm{~cm}^{3}$ polyethylene vial. They were covered with cotton wool and the top of the polyethylene vial properly sealed with a celotape. The characteristics of the detector thin foils and wire used are shown in Table 1.

The set of monitors $\mathrm{Al}-0.1 \% \mathrm{Au}, \mathrm{Zr}$ and $\mathrm{Zn}$ thin foils and the Mo thin wire in the $25 \mathrm{~cm}^{3}$ polyethylene vial were irradiated simultaneously in the Cd lined irradiation channel of the NIRR-1 at a preset thermal neutron flux of $5 \times 10^{11} \mathrm{n} \cdot \mathrm{cm}^{-2} \cdot \mathrm{s}^{-1}$ for 3 hours. The induced activities on the irradiated set of monitors were measured using the full energy peak efficiency calibrated P-type GEM 30195 HPGe coaxial detector system at the distance of 2 $\mathrm{cm}$ from the detector. The energy resolution of the detector system is $1.95 \mathrm{keV}$ for the $1332 \mathrm{keV}$ peak of ${ }^{60} \mathrm{Co}$ and the relative detector efficiency is 30\%. The full energy peak efficiency of the P-type GEM 30195 HPGe coaxial detector was measured at the distances $2 \mathrm{~cm}$ and $15 \mathrm{~cm}$ from the detector over the energy range 59.54 $-1408 \mathrm{keV}$ using the set of IAEA standard sources ${ }^{241} \mathrm{Am},{ }^{152} \mathrm{Eu}{ }^{226} \mathrm{Ra},{ }^{137} \mathrm{Cs},{ }^{60} \mathrm{Co}$ and ${ }^{22} \mathrm{Na}$. A detailed description of the measured full energy peak efficiency curves and the theoretical fitting function to the experimental efficiency curves is given elsewhere [3].

The product nuclides ${ }^{69 \mathrm{~m}} \mathrm{Zn},{ }^{198} \mathrm{Au},{ }^{97} \mathrm{Zr}$ and ${ }^{99} \mathrm{Mo}$ were counted for 3600 seconds within one day after irradiation of the $\alpha$ monitors. The product nuclides ${ }^{65} \mathrm{Zn}$ and ${ }^{95} \mathrm{Zr}$ were counted for 72000 seconds after $14.91-14.99$ days. The photopeak areas of the gamma-ray energies for the product nuclides of the irradiated $\alpha$ monitors were 
obtained from the gamma-ray acquisition system of the P-type GEM 30195 HPGe coaxial detector system that consists of the Maestro Multicannel Annalyser (MCA) emulation software card coupled to the detector via electronic nuclear Instrumentation modules manufactured by Ortec.

Table 2 shows the nuclear data for the product nuclides of the four monitors irradiated for $\alpha$ determination in the Cd lined irradiation channel of the NIRR-1. The efficiencies $\varepsilon$ of the gamma-ray energies for the product nuclides of the four monitors were calculated by the authors using mathematical fitting functions described elsewhere [3]. The specific activities $A_{\mathrm{sp} \text { (Cd) }}$ for each of the product nuclides of the four monitors were also calculated by the authors. The nuclear data $\overline{\mathrm{E}}_{\mathrm{r}}, Q_{o}, \mathrm{~F}_{\mathrm{Cd}}$ and $k_{o, \mathrm{Au}}$-factors were obtained from the literature [4]-[8].

\section{Results and Discussions}

The $\alpha$ value was determined by solving Equation (1) by the iterative linear regression method based on MS Excel spreadsheet. Starting with step 1 by setting $\alpha=0$ resulted in the value of $\alpha_{1}=-0.123 \pm 0.020$. The finalvalue of $\alpha$ was obtained after four iterative procedures. The third and fourth iterations both led to $\alpha_{3}$ and $\alpha_{4}$ equal to $-0.137 \pm 0.018$. Thus, the final value of $\alpha$ by the iterative procedure was $-0.137 \pm 0.018$.

Furthermore, the epithermal neutron flux value in the Cd lined irradiation channel at the preset power of the NIRR-1 was determined using the peak area of the $411.8 \mathrm{keV}$ gamma-ray line from ${ }^{198} \mathrm{Au}$.

Table 3 shows the values of the epithermal neutron shape factor $(\alpha)$ and the epithermal neutron flux determined in the Cadmium lined irradiation channel of the NIRR-1. From Table 3, the value of $\alpha$ is negative. The negative value of $\alpha$ indicates a hardened (poorly thermalized) epithermal neutron spectrum in the Cd lined irradiation channel of the NIRR-1.

Also from Table 3, the value of epithermal neutron flux calculated using the activity of ${ }^{198} \mathrm{Au}$ in $\mathrm{Al}-0.1 \% \mathrm{Au}$ thin foil in the monitor set irradiated for $\alpha$ determination in the cadmium lined irradiation channel of the NIRR-1 was found to be $(4.51 \pm 0.09) \times 10^{9} \mathrm{n}^{\cdot} \mathrm{cm}^{-2} \cdot \mathrm{s}^{-1}$. This value is comparable to a theoretical value of $5.05 \times 10^{9}$ $\mathrm{n} \cdot \mathrm{cm}^{-2} \cdot \mathrm{s}^{-1}$ in the outer irradiation site A2 of the NIRR-1 based on the assumption that the thermal neutron flux values in the outer irradiation sites are $50 \%$ of the values in the inner irradiation sites [9]. The thermal to epithermal neutron flux ratio in the outer irradiation site A2 of the NIRR-1 has been found to be approximately $49.5 \pm 0.96$ [9] as shown in Table 4. It should be noted that the channel A2 is now the channel A3 that has been lined with the $1.00 \mathrm{~mm}$ thick Cd-liner.

Table 4 shows a comparison of the $\alpha$ values in the Cd lined irradiation channel with results of other irradiation sites of the NIRR-1 and other miniature neutron source reactors [9]-[12]. From Table 4, it can be observed that due to the installation of the Cd liner in one of the outer irradiation channels, the $\alpha$ value is different from the old data in similar outer irradiation sites of the NIRR-1. The high negative value of $\alpha$ in the cadmium lined

Table 1. Description of the activation detector foils and wire for $\alpha$ determination.

\begin{tabular}{cccc}
\hline Element & Material description & Diameter $(\mathrm{cm})$ & Mass $(\mathrm{g})$ \\
$\mathrm{Au}$ & Al-0.1\%Au thin foil, 0.1mm thick,IRMM-530 & 0.8 & 0.0132 \\
$\mathrm{Zn}$ & $99.95 \%$ Zn foil, 0.025 mm thick, Goodfellow & 0.8 & 0.0083 \\
$\mathrm{Zr}$ & $99.8 \%$ Zr foil, 0.125 mm thick, Goodfellow & 0.8 & 0.0446 \\
$\mathrm{Mo}$ & Thin wire & & 0.0168 \\
\hline
\end{tabular}

Table 2. Nuclear data for the product nuclides of 4 monitors irradiated for $\alpha$ determination in the Cd lined irradiation channel.

\begin{tabular}{|c|c|c|c|c|c|c|c|c|c|}
\hline Target nucleus & $\begin{array}{l}\text { Product } \\
\text { nucleus }\end{array}$ & Half life & $\mathrm{E}_{\gamma}(\mathrm{keV})$ & $\overline{\mathrm{E}}_{\mathrm{r}}(\mathrm{eV})$ & $Q_{o}$ & $\begin{array}{c}k_{o, \mathrm{Au}} \\
\text { factors }\end{array}$ & $\mathrm{A}_{\mathrm{sp}(\mathrm{Cd})}(\mathrm{C} / \mathrm{s} . \mathrm{g})$ & $\varepsilon$ & $F_{\text {Cd }}$ \\
\hline${ }^{197} \mathrm{Au}$ & ${ }^{198} \mathrm{Au}$ & $2.70 \mathrm{~d}$ & 411.8 & 5.65 & 15.71 & 1 & $5.43 \times 10^{8}$ & 0.0212 & 0.991 \\
\hline${ }^{64} \mathrm{Zn}$ & ${ }^{65} \mathrm{Zn}$ & $243.9 \mathrm{~d}$ & 1115.5 & 2560 & 1.908 & $5.72 \times 10^{-3}$ & $5.02 \times 10^{5}$ & 0.00784 & 1 \\
\hline${ }^{68} \mathrm{Zn}$ & ${ }^{69 m} \mathrm{Zn}$ & $13.76 \mathrm{~h}$ & 438.6 & 590 & 3.19 & $3.98 \times 10^{-4}$ & $8.49 \times 10^{4}$ & 0.0197 & 1 \\
\hline \multirow[t]{2}{*}{${ }^{94} \mathrm{Zr}$} & ${ }^{95} \mathrm{Zr}$ & $64.02 \mathrm{~d}$ & 724.2 , & 6260 & 5.05 & $9.32 \times 10^{-5}$ & $1.27 \times 10^{4}$ & 0.0110 & 1 \\
\hline & & & 756.7 & & & $1.15 \times 10^{-4}$ & $1.53 \times 10^{4}$ & 0.0105 & 1 \\
\hline${ }^{96} \mathrm{Zr}$ & ${ }^{97} \mathrm{Zr}$ & $16.74 \mathrm{~h}$ & 743.4 & 338 & 248 & $1.30 \times 10^{-5}$ & $4.06 \times 10^{4}$ & 0.0107 & 1 \\
\hline${ }^{98} \mathrm{Mo}$ & ${ }^{99} \mathrm{Mo}$ & $65.94 \mathrm{~h}$ & 140.51 & 241 & 53.1 & $5.27 \times 10^{-4}$ & $1.73 \times 10^{6}$ & 0.0336 & 1 \\
\hline
\end{tabular}


irradiation channel indicates a hardened (poorly thermalized) epithermal neutron spectrum in the cadmium lined irradiation channel (A3) of the NIRR-1. This is to be expected because the thermal neutron component of the reactor neutron spectrum has been highly cut-off by the $1.00 \mathrm{~mm}$ thick cadmium of the cadmium lined irradiation channel causing the neutron spectrum to be shifted to higher energies in the epithermal region.

In order to test the $\alpha$ value obtained, the concentrations of Sm and $\mathrm{Br}$ in the NIST 1515 Apple leaves were determined by the single comparator method of epithermal neutron activation analysis ( $k_{0}$-ENAA) in the cadmium lined irradiation channel of the NIRR-1. The standard reference materials NIST 1515 Apple leaves was irradiated together with the $\mathrm{Al}-0.1 \% \mathrm{Au}$ thin foil as the single comparator in the Cd lined irradiation channel at a preset thermal neutron flux of $5 \times 10^{11} \mathrm{n}^{\cdot} \mathrm{cm}^{-2} \cdot \mathrm{s}^{-1}$ for 6 hours. The induced activities on the elements of interest in the samples of NIST 1515 Apple leaves were measured under the same counting conditions at the distance of $2 \mathrm{~cm}$ from the efficiency calibrated P-type GEM 30195 HPGe coaxial detector system after appropriate decay and counting periods.

The concentrations of the elements determined in the NIST 1515 Apple leaves were calculated by the $k_{o}$-ENAA method with the MS Excel spreadsheet using the equation [13]

$$
C_{s(\mathrm{Cd})}=\left[\frac{\left(\frac{N_{p, s} / t_{c}}{S D C W}\right)_{s}}{\left(\frac{N_{p, \mathrm{Au}} / t_{c}}{S D C w_{\mathrm{Au}}}\right)_{\mathrm{Au}}}\right]_{\mathrm{Cd}} \cdot\left[\frac{F_{\mathrm{Cd}, \mathrm{Au}} \cdot Q_{o}(\alpha)_{\mathrm{Au}} \cdot \varepsilon_{d, \mathrm{Au}}}{k_{o(\mathrm{Au})} F_{\mathrm{Cd}, s} Q_{o}(\alpha)_{s} \varepsilon_{d, s}}\right]
$$

where the $k_{o, \mathrm{Au}}$ factor is a compound nuclear constant of the nuclide in the sample of material with respect to $\mathrm{Au}[14]$

$M_{\mathrm{Au}}=$ atomic mass of gold,

$M_{s}=$ atomic mass of the element of interest in the sample,

$\theta_{s}=$ isotopic abundance of the element of interest in the sample,

$\theta_{\mathrm{Au}}=$ isotopic abundance of gold,

$\varepsilon_{\gamma, s}=\gamma$-ray intensity of the element of interest in the sample,

Table 3. Results of neutron spectrum parameters in the Cd lined irradiation channel.

\begin{tabular}{ccc}
\hline Irradiation channel & $\alpha$ & $\Phi_{e}\left(\mathrm{n} \cdot \mathrm{cm}^{-2} \cdot \mathrm{s}^{-1}\right)$ \\
\hline Cd lined (A3) & $-0.137 \pm 0.018$ & $(4.51 \pm 0.09) \times 10^{9}$ \\
\hline
\end{tabular}

Table 4. Comparison of the $\alpha$ values in the Cd lined irradiation channel with results in other irradiation sites of the NIRR-1 and other MNSRs.

\begin{tabular}{|c|c|c|c|c|}
\hline \multirow[t]{2}{*}{ Facility } & \multicolumn{2}{|c|}{ Inner Channel } & \multicolumn{2}{|c|}{ Outer Channel } \\
\hline & $f$ ratio & $\alpha$ & $f$ ratio & $\alpha$ \\
\hline $\begin{array}{c}\text { Prototype MNSR, } \\
\text { Beijing, China, } 27 \mathrm{~kW}, 90.2 \% \\
{ }^{235} \mathrm{U} \text { (Sites: Inner and outer) }\end{array}$ & $19.8 \pm 0.4$ & $-0.009 \pm 0.004$ & $58.5 \pm 3$ & $+0.023 \pm 0.010$ \\
\hline $\begin{array}{l}\text { GHARR-1 MNSR, Accra, Ghana, } 30 \mathrm{~kW}, 90.2 \% \\
{ }^{235} \mathrm{U} \text { (Sites:1—inner, 10-outer) }\end{array}$ & 18.8 & -0.104 & 49.0 & -0.0261 \\
\hline $\begin{array}{l}\text { GHARR-1 MNSR, Accra Ghana, 30kW, } 90.2 \% \\
\text { 235U(Sites: 5-inner, 7-outer) }\end{array}$ & 17.28 & $-0.107 \pm 0.001$ & 40.38 & $-0.173 \pm 0.0001$ \\
\hline $\begin{array}{l}\text { NIRR-1 MNSR, Zaria, Nigeria, 90.2\% } \\
{ }^{235} \mathrm{U} \text { (Sites: B2—inner, B4—outer) }\end{array}$ & $19.2 \pm 0.5$ & $-0.052 \pm 0.002$ & $48.3 \pm 3.3$ & $+0.029 \pm 0.003$ \\
\hline $\begin{array}{l}\text { NIRR-1 MNSR, Zaria, Nigeria, 30kW, 90.2\% } \\
{ }^{235} \text { U(Sites: A1—inner, A2—outer) }\end{array}$ & $18.4 \pm 0.34$ & $-0.046 \pm 0.005$ & $49.5 \pm 0.96$ & $+0.024 \pm 0.002$ \\
\hline $\begin{array}{l}\text { NIRR-1 MNSR, Zaria, Nigeria, 30kW, 90.2\% } \\
{ }^{235} \text { U(Sites: A3(Cd Lined Channel)) }\end{array}$ & & & & $-0.137 \pm 0.018$ \\
\hline
\end{tabular}


$\varepsilon_{\gamma, \mathrm{Au}}=\gamma$-ray intensity of gold,

$\sigma_{o, s}=$ thermal neutron cross section of elements of interest in the sample,

$\sigma_{o, \mathrm{Au}}=$ thermal neutron cross section for Au,

$F_{\mathrm{Cd}, \mathrm{Au}}=$ the cadmium epithermal neutron transmission factor for gold,

$F_{\mathrm{Cd}, \mathrm{s}}=$ the cadmium epithermal neutron transmission factor for elements in sample,

$Q_{o}(\alpha)_{\mathrm{Au}}=$ corrected resonance integral to the thermal neutron cross sections for gold in the Cd lined irradiation channel,

$Q_{o}(\alpha)_{s}=$ corrected resonance integral to the thermal neutron cross sections for the elements in the sample in the Cd lined irradiation channel,

$\alpha=$ measured epithermal neutron shape factor in the Cd lined irradiation channel,

$\varepsilon_{d, s}=$ detector efficiency for $\gamma$-ray energy of nuclide in sample,

$\varepsilon_{d, \mathrm{Au}}=$ detector efficiency for $\gamma$-ray energy of ${ }^{198} \mathrm{Au}$,

$W_{s}=$ total amount of sample irradiated,

$C_{s}=$ concentrations of the unknown element in samples irradiated in the Cd lined irradiation channel $\left(\mathrm{mg} \cdot \mathrm{kg}^{-1}\right)$,

$w_{s}=$ calculated unknown weight of element in sample,

$w_{\mathrm{Au}}=$ weight of the sample of gold foil,

$N_{p, s}=$ Net photopeak area of radionuclide of interest in sample,

$N_{p, \text { Au }}=$ Net photopeak area of ${ }^{198} \mathrm{Au}$,

$D=\mathrm{e}^{-\lambda t_{d}}=$ decay factor for gold or elements of interest in sample,

$S=\left(1-\mathrm{e}^{-\lambda t_{i}}\right)=$ saturation factor for gold or elements of interest in sample,

$C=\frac{\left(1-\mathrm{e}^{-\lambda t_{c}}\right)}{\lambda t_{c}}=$ correction factor for decay during counting for gold or elements in sample,

$\lambda=$ decay constant, $t_{i}=$ irradiation time,$t_{d}=$ decay time,$t_{c}=$ counting time.

The results of the concentrations of the elements determined in the NIST 1515 Apple leaves by $k_{o}$-ENAA are shown in Table 5.

From Table 5, the elements Sm and Br with high $Q_{o}$ values were determined in the NIST 1515 Apple leaves by the $k_{o}$-ENAA method. The elements Sm and Br strongly absorb neutrons of specific resonance energies in the epithermal neutron region. These elements have high resonance activation integrals compared to their thermal neutron cross sections in the epithermal neutron region. The concentrations of Sm and $\mathrm{Br}$ in the NIST 1515 Apple leaves are in good agreement with the certified values. The $k_{o}$-ENAA method in the cadmium lined irradiation can be regarded as a reliable method of neutron activation analysis (NAA) in the NIRR-1. It can be used for the determination of bromine in bread to control the illegal use of potassium bromate $\left(\mathrm{KBrO}_{3}\right)$ in bread making in Nigeria.

\section{Conclusions}

The value of the epithermal neutron shape factor $(\alpha)$ and epithermal neutron flux $\left(\varphi_{e}\right)$ in the permanent cadmium lined irradiation channel installed in the large outer irradiation site of the NIRR-1 have been determine for the purpose of adopting the $k_{o}$-ENAA method in the NIRR-1 NAA laboratory. The value of $\alpha$ was determined by the cadmium covered multimonitor method using the monitors Al-0.1\% Au, $\mathrm{Zr}$ and $\mathrm{Zn}$ thin foils and Mo thin

Table 5. Results of concentrations of elements determined in NIST 1515 Apple leaves by $k_{o}$-ENAA in mg $\mathrm{kg}^{-1}$.

\begin{tabular}{ccc}
\hline Element & Certified $\left(\mathrm{mg} \cdot \mathrm{kg}^{-1}\right)$ & This work (mg.kg $\left.{ }^{-1}\right)$ \\
$\mathrm{Sm}$ & 3.00 & $2.44 \pm 0.04$ \\
$\mathrm{Br}$ & 1.80 & $1.80 \pm 0.27$ \\
\hline
\end{tabular}


wire and was found to be $-0.137 \pm 0.018$. The epithermal neutron flux was found to be $(4.51 \pm 0.09) \times 10^{9}$ $\mathrm{n} \cdot \mathrm{cm}^{-2} \cdot \mathrm{s}^{-1}$. The high negative value of $\alpha$ indicates a hardened epithermal neutron spectrum in the cadmium lined irradiation channel.

The $\alpha$ value obtained was used in the single comparator method of ENAA ( $k_{0}$-ENAA) for the determination of the concentrations of elements in the SRM NIST 1515 Apple leaves using Al-0.1\% Au thin foil as the single comparator. The concentrations of the elements Sm and Br with high $Q_{o}$ values determined in the NIST 1515 Apple leaves are in good agreement with the certified values. This is an important evidence of the reliability of the result of the $\alpha$ value obtained.

\section{Acknowledgements}

The authors are thanking the management of the Centre for Energy Research and Training, Ahmadu Bello University, Zaria, Nigeria and members of staff of the Nuclear Science and Technology Section, Centre for Energy Research and Training, Ahmadu Bello University, Zaria, Nigeria for their assistance in the experimental work of this study.

\section{References}

[1] Abubakar, N. (2014) Steady State Thermal Hydraulic Analysis of Highly Enriched Uranium (HEU) Core of the Nigeria Nuclear Research Reactor-1 (NIRR-1) Using PLTEMP Code, M. ENG. Energy Engineering Dissertation, Bayero University, Kano, 2.

[2] De Corte, F., Sordo-El Hammami, K., Moens, L., Simonits, A., De Wispelaere, A. and Hoste, J. (1981) The Accuracy and Precision of the $\alpha$-Determination in the $\frac{1}{E^{1+\alpha}}$ Epithermal Reactor Neutron Spectrum. Journal of Radioanalytical and Nuclear Chemistry, 62, 209-255. http://dx.doi.org/10.1007/BF02517354

[3] Sheyin, F.T. (2015) Characterization of the Cadmium Lined Irradiation Channel of the Nigeria Research Reactor-1 (NIRR-1) and Its Application for Elemental Determination in Some Legumes. Ph.D. Thesis, Ahmadu Bello University, Zaria.

[4] De Corte, F. and Simonits, A. (2003) Recommended Nuclear Data for Use in the $k_{o}$-Standardization of Neutron Activation Analysis. Atomic Data and Nuclear Data Tables, 85, 47-67. http://dx.doi.org/10.1016/S0092-640X(03)00036-6

[5] De Corte, F., Simonits, A., De Wispelaere, A. and Elek, A. (1989) $k_{o}$-Measurements and Related Nuclear Data Compilation For (n, $\gamma$ ) Reactor Neutron Activation Analysis, IIIa: Experimental. Journal of Radioanalytical and Nuclear Chemistry, Articles, 133, 3-41.

[6] De Corte, F. and Simonits, A. (1989) $k_{o}$-Measurements and Related Nuclear Data Compilation For (n, $\gamma$ ) Reactor Neutron Activation Analysis, IIIb: Tabulation. Journal of Radioanalytical and Nuclear Chemistry, Articles, 133, 43130.

[7] A. Simonits,L. Moens, F. De Corte, A. De Wispelaere, A. Elek, J. Hoste, (1980) $k_{o}$-Measurements and Related Nuclear Data Compilation For (n, $\gamma$ ) Reactor Neutron Activation Analysis, Part I: Journal of Radioanalytical and Nuclear Chemistry, 60, 461-516. http://dx.doi.org/10.1007/BF02518906

[8] El Nimr, T., De Corte, F., Moens, L. and Hoste, J. (1981) Epicadmium Neutron Activation Analysis (ENAA) Based on the $k_{o}$-Comparator Method. Journal of Radioanalytical and Nuclear Chemistry, 67, 421-430. http://dx.doi.org/10.1007/BF02516355

[9] Sadiq, U., Jonah, S.A., Nasiru, R. and Zakari, Y.I. (2010) Neutron Spectrum Parameters in Two Irradiation Channels of the Nigeria Research Reactor-1 (NIRR-1) for Use in $k_{o}$-NAA. Bayero Journal of Pure and Applied Sciences, 3, 220223. http://dx.doi.org/10.4314/bajopas.v3i1.58797

[10] Jonah, S.A., Balogun, G.I., Umar, I.M. and Mayaki, M.C. (2005) Neutron Spectrum Parameters in Irradiation Channels of the Nigeria Research Reactor-1 (NIRR-1) for the $k_{o}-N A A$ Standardization. Journal of Radioanalytical and Nuclear Chemistry, 266, 83-88. http://dx.doi.org/10.1007/s10967-005-0873-8

[11] Kennedy, G., St.-Pierre, J., Wang, K., Zhang, Y., Preston, J., Grant, C. and Vutchkov, M. (2000) Activation Constants for Slowpoke and MNS Reactors Calculated from the Neutron Spectrum and $k_{o}$ and $Q_{o}$ Values. Journal of Radioanalytical and Nuclear Chemistry, 245, 167-172. http://dx.doi.org/10.1023/A:1006749820638

[12] Ahmed, Y.A. (2004) Characterization of Irradiation Channels of the GHARR-1 Miniature Neutron Source Reactor. 
M.Sc. Thesis, Ahmadu Bello University, Zaria, 43-48.

[13] De Corte, F., Dejaeger, M., Hossain, S.M., Vandenberghe, D., De Wespelaere, A.P. and Van den Haute, P. (2005) A Perfomance Comparison of $k_{o}$-Based ENAA and NAA in the (K,Th,U) Radiation De Rate Assessment for Luminescence Dating of Sediments. Journal of Radioanalytical and Nuclear Chemistry, Articles, 263, 659-665.

[14] Simonits, A., De Corte, F. and Hoste, J. (1975) Single Comparator Methods in Reactor Neutron Activation Analysis. Journal of Radioanalytical and Nuclear Chemistry, 24, 31-46. http://dx.doi.org/10.1007/BF02514380 